\title{
Germination improves sensory, phenolic, protein content and anti-inflammatory properties of red kidney bean (Phaseolus vulgaris L.) sprouts milk
}

\author{
${ }^{1 *}$ Winarsi, H., ${ }^{2}$ Septiana, A.T. and ${ }^{3}$ Wulandari, S.P. \\ ${ }^{1}$ Department of Nutrition Science, Faculty of Health Sciences, Universitas Jenderal Soedirman, Purwokerto, \\ 53123, Central Java, Indonesia \\ ${ }^{2}$ Department of Food Technology, Faculty of Agriculture, Universitas Jenderal Soedirman, Purwokerto, \\ 53123, Central Java, Indonesia \\ ${ }^{3}$ Department of Pharmacy, Faculty of Health Sciences, Universitas Jenderal Soedirman, Purwokerto, \\ 53123, Central Java, Indonesia
}

\begin{abstract}
Article history:
Received: 23 April 2020

Received in revised form: 29

May 2020

Accepted: 2 June 2020

Available Online: 27 July

2020
\end{abstract}

\section{Keywords:}

Phenolic,

Soluble protein,

Red kidney bean sprout milk,

Sensory,

Anti-inflammatory,

Germination

DOI:

https://doi.org/10.26656/fr.2017.4(6).188

\begin{abstract}
Germination can minimize beany flavor, change phytochemical compounds, and functional properties. Better acceptance of germination-based products; likewise, soluble protein is good for diet-related to metabolic syndrome which is known to experience inflammation. Phenolic, one of the phytochemicals is antioxidant and has the potential to be anti-inflammatory. This study aimed to determine the effect of germination time on sensory, total phenolic, and soluble protein contents of red kidney bean sprouts milk (RKBSM), and its anti-inflammatory effect. The red kidney beans were germinated for 0 , 10,20 , and $30 \mathrm{hrs}$. With a ratio of 1: 8 , the red kidney bean sprouts and water were blended, filtered, and add with $5 \%$ sugar. The sensory test (color, taste, flavor, and viscosity) was performed by using the 5-point hedonic scale, extremely dislike (1) to extremely like (5); determination of total phenolic by the Folin-Ciocalteu, and soluble protein with Lowry method. The anti-inflammatory test using the hind paw edema method using carrageenan-induced rats. The selected formula was RKBSM with $30 \mathrm{hrs}$ of germination with neutral-moderately like score sensory, and rich in phenolic antioxidants $(583.85 \mathrm{mg} / \mathrm{L})$, protein $(6.54 \%)$, and soluble protein $(33.65 \%)$, but low in fat $(0.1 \%)$ and carbohydrates (4.48\%). The higher the phenolic dose of the selected RKBSM $(8 \mathrm{mg} / \mathrm{Kg}$ BW), the higher the anti-inflammatory potency (44.74\%) and the motility score (1.42). Longer germination time, higher total phenolic, and soluble protein. Higher phenolic levels increased the anti-inflammatory effect in carrageenan-induced rats.
\end{abstract}

\section{Introduction}

Red kidney bean (Phaseolus vulgaris L.) is known to be high in fiber (4\%), protein (29.1\%), unsaturated fatty acids, and vitamin E (Hayat et al., 2014). It also contains a large number of phytochemical compounds including phenolic, flavonoids, vitexin, and isovitexin (Luo et al., 2016). It has the highest antioxidant activity compared to other types of legumes (Kiyani-Sam et al., 2015). Legumes are generally rich in polyphenols which are proven to protect LDL against oxidation and reduce LDL absorption (Winarsi et al., 2012). The bean also contains resistant starch, vitamins, and fructooligosaccharides which have been proven to protect the body from oxidative stress, heart disease, diabetes, cancer, and metabolic syndrome (MetS) (Oomah et al., 2010). Like other legumes, the red kidney beans contain anti- nutrients that often bother the consumers. Germination is one of the methods to minimize the anti-nutrients.

During the germination of red kidney beans, there is an increase in the secretion of hormones and enzymes that hydrolyze food reserves, transport the soluble food and hormones to the growth point, and assimilation (photosynthesis). The germination also causes the activation of hydrolases (protease, lipase, and carbohydrase). The protease immediately converts protein molecules into amino acids, the starch deposits are broken down by carbohydrase into maltose and then glucose, and the fat content is broken down by lipase into fatty acids (Chaudhary et al., 2013). Therefore, the amino acids, fatty acids, and glucose contents of red kidney bean sprouts are higher than the un-germinated red kidney beans. 
The previous studies have reported that germination time affects the phenolic content, as well as the protein content (Martinez et al., 2012). Germination can cause changes in phytochemical compounds and their functional properties due to aerobic respiration and biochemical metabolism. There are several antioxidants and antioxidant-related substances in sprouts. The highest contents in sprouts are phytosterols, vitamin E, phenolic, and some minerals. Nguyen et al. (2015) added that phenolic has the potential to be anti-inflammatory. Protein-rich products can make you feel full longer. Thus, the next energy intake can be suppressed which results in weight loss (Winarsi et al., 2016). Besides that, germination eliminates some antinutrients and flatulence -causing compounds; thereby, improving the acceptability of the processed product such as RKBSM. However, until now there has not been found a preferred RKBSM formula, rich in protein and antioxidants, which has the potential to be anti-inflammatory. Therefore, this study aimed to obtain the best RKBSM formula based on sensory, phenolic antioxidant and protein content. In addition, it is also to find out the anti-inflammatory potential of the RKBSM.

\section{Materials and methods}

This experimental study used a completely randomized design with several stages. All animal experiments were equipped with ethical clearance obtained from the Faculty of Medicine, University of Jenderal Soedirman, Purwokerto, Central Java, Indonesia, with Number Ref: 3428/KEPK/VIII /2018, August 1, 2018.

\subsection{Production of red kidney bean sprouts}

The red kidney beans were sorted, separated from various impurities, washed with running water, soaked for $12 \mathrm{hrs}$, and then drained. The red kidney beans were germinated in a plastic basket container with a moistened flannel cloth under the basket, then covered with a dark cloth. The germination was employed for $0,10,20$, and $30 \mathrm{hrs}$ at room temperature so that the length of the sprouts reached $0.5-1.5 \mathrm{~cm}$ and did not have branched roots. Every eight hrs, $10 \mathrm{~mL}$ of water was sprinkled evenly on $50 \mathrm{~g}$ of red kidney beans (Okereke, 2008).

\subsection{Production of red kidney bean sprout milk (RKBSM)}

The red kidney bean sprouts were washed thoroughly without peeling the skin. The sprouts and water were blended in a blender at high speed with a ratio of $1 \mathrm{~kg}$ of red kidney bean sprouts to $8 \mathrm{~L}$ of water. After blending, the sprouts and water were filtered using a filter cloth so that a white liquid called RKBSM was obtained. After adding 5\% of sugar, RKBSM was heated at $80^{\circ} \mathrm{C}$ for 45 mins while stirring. The boiled milk was then put into a bottle and cooled at room temperature (Fidelis et al., 2014).

\subsection{Sensory test}

The sensory test using by a hedonic test was performed by fifty-five untrained panelists (panelists who had an average ability level and did not receive formal training) (Moskowitz et al., 2012). Sensory tests included the tests on color, taste, flavor, and viscosity attributes using 5-point hedonic scale questionnaire method as follows: $1=$ extremely dislike, $2=$ moderately dislike, $3=$ neutral, $4=$ moderately like, and 5=extremely like.

\subsection{Determination of total phenolic content}

The analysis of total phenolic content was performed following the Folin-Ciocalteu method in Amirdivani and Baba (2015). A triplicate testing was performed.

\subsection{Determination of soluble protein content}

The soluble protein content was determined following the Lowry method (Pomory, 2008). Triplicate testing was performed. The sample was weighed $1 \mathrm{~g}$ into a measuring flask and added with $10 \mathrm{~mL}$ distilled water. The mixture was transferred into an Erlenmeyer flask and shook for $15 \mathrm{mins}$ at $157 \mathrm{rpm}$. About $1 \mathrm{~mL}$ of the mixture was sampled and added with $8 \mathrm{~mL}$ of Lowry B reagent. It was left for 10 mins and then added with 1 $\mathrm{mL}$ of Lowry A before standing for 20 mins. The absorbance at a wavelength of $600 \mathrm{~nm}$ was measured and calculated with the formula:

Dissolved protein levels $(\% \mathrm{wb})=(\mathrm{X} \times \mathrm{DF} \times 100) /$ (initial sample weight $(\mathrm{mg})) \times 100 \%$

Where $\mathrm{X}$ is the protein concentration and DF is the diluent factor.

\subsection{Anti-inflammatory test}

\subsubsection{Preparation of 1\% carrageenan suspension}

Carrageenan was weighed as much as $0.1 \mathrm{~g}$, adding a physiological solution of $0.9 \% \mathrm{NaCl}$ to a volume of 10 mL (Pradeepkumar et al., 2015).

\subsubsection{Determination of RKBSM anti-inflammatory} activity in animal trial

Anti-inflammatory activity was carried out by the rat hind paw edema method using carrageenan as induction of acute inflammation (Singh et al., 2008). The activity was calculated as the percentage of anti-inflammatory potency and motility score. Male Wistar rats 25 tails, aged 2-3 months, weighing 110-150 g were adapted for 1 week and fasted for 18 hours, while drinking water was 
still given before treatment. On the day of testing, rats were divided into five groups randomly with five each. Each rat is weighed and foot volume is measured. The left leg of all rats was injected with $0.1 \mathrm{~mL}$ of carrageenan suspension sub-plantar and waited for 15 mins.

The next intervention was as follows: group I, Negative control, given distilled water; II, positive control, was given sodium diclofenac, $4.5 \mathrm{mg} / \mathrm{Kg} \mathrm{BW}$ rats; III, IV, and V were given RKBSM with total phenolic equivalent of gallic acid 4,6 , and $8 \mathrm{mg} / \mathrm{Kg} \mathrm{BW}$ respectively. After 30 mins of intervention, the volume of the left leg is measured by dipping the rat's leg into the plethysmometer which is expressed as Vt. Measurements were made with testing time intervals every $30 \mathrm{mins}$ for $4 \mathrm{hrs}$ (Vazirian et al., 2014). Percentage increase in foot volume rat edema calculated based on the following formula:

$\%$ Increase in edema volume $=\frac{(\mathrm{Vt}-\mathrm{Vo})}{\mathrm{Vo}} \times 100 \%$

Where $\mathrm{Vt}=$ Volume of legs after carrageenan injection, and $V_{o}=$ Volume of legs before carrageenan injection

After obtaining the data of $\%$ increase in the volume of edema, then a relationship curve for the percentage increase in edema volume with time. Then calculated Area Under Curve (AUC) with the following formula:

$$
A U C_{t n-1}^{t n}=\frac{V t_{n-1}+V t_{n}}{2}\left(t_{n}-t_{n-1}\right)
$$

Where $\mathrm{Vt}_{\mathrm{n}-1}=$ the average volume of edema on $\mathrm{t}_{\mathrm{n}-1} ; \mathrm{Vt}_{\mathrm{n}}=$ the average volume of edema on $t_{n}$.

The anti-inflammatory potency of RKBSM is determined by the following formula:

$$
\% \text { Anti }- \text { inflammatory potency }=\frac{\text { AUC control-AUC treatment }}{\text { AUC treatment }} \times 100 \%
$$

While, the motility test is testing rat behavior, which was observed every 5 mins for 4 hrs The scores were: 0 , if the rat goes with difficulty and avoids the inflamed toes touching the floor; 1 , if the rat goes with a little difficulty but its feet touch the floor; and 2, if rat goes easily (Amdekar et al., 2011).

\subsection{Statistical analysis}

The total phenolic and protein contents were analyzed by using Analysis of variance (ANOVA). If there was a significant effect, the analysis was continued with Duncan's Multiple Range Test (DMRT) at a 5\% significance level. The sensory variables were analyzed using the Friedman test. If there was a significant result, the multiple comparison tests were performed at a 5\% significance level. The effectiveness index was used to find out the best RKBSM formula based on the aspects of sensory, phenolic, and soluble protein content. The anti-inflammatory potency was analyzed by Kolmogorov
Smirnov, followed by one-way ANOVA and LSD test, while the motility score was analyzed using the Kruskal Wallis non-parametric test and the Mann Whitney U-test.

\section{Results and discussion}

\subsection{Effect of germination times on sensory RKBSM}

There was an effect of germination time on the preference of RKBSM taste $(P<0.05)$. The highest taste score was found in the RKBSM with a $20 \mathrm{~h}$ germination time (3.25), but the score was not significantly different $(P>0.05)$ from the RKBSM with a $30 \mathrm{~h}$ germination time (3.05) (Figure 1). It means that the longer the germination time, the sweeter the taste of RKBSM. The germination process can reduce the glycosides saponins and sapogenin contents which cause a bitter taste in legumes and then convert them to sugar. The results of this study were similar to the findings of Murugkar (2014) and Ojha et al. (2014) which showed that the taste of soybean sprout milk and the taste of tofu made from soybean sprout milk was preferred than the ordinary soy milk and the tofu made from the ungerminated - soybean milk because the germination could improve the sensory properties of the product. With the germination, many compounds turn into precursors and contribute to providing a delicious taste. The delicious taste makes consumers feel comfortable in consuming the product. The amino acids resulting from the breakdown of proteins with the reducing sugars formed a delicious taste and flavor compound in the food. The milk made from red kidney beans had the most delicious taste compared to soybeans or cowpea.

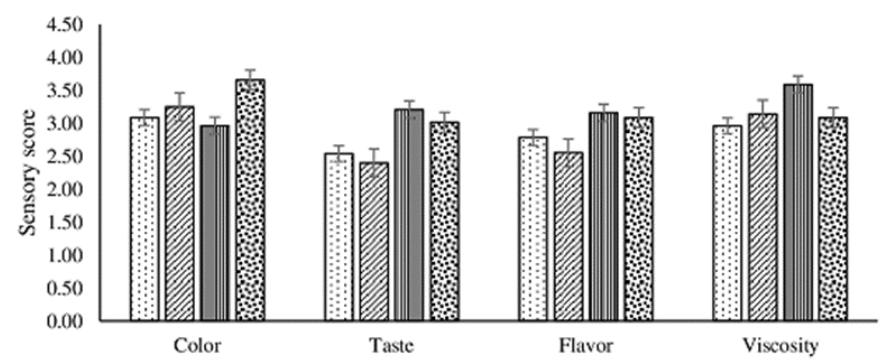

Figure 1. Effect of germination time on sensory score of red kidney bean sprouts milk. $0 \mathrm{hr}$, Ungerminated red kidney beans; $10 \mathrm{hrs}$, Red kidney beans germinated for $10 \mathrm{hrs;} 20 \mathrm{hrs,}$ Red kidney beans germinated for $20 \mathrm{hrs;} 30 \mathrm{hrs}$, Red kidney beans germinated for $30 \mathrm{hrs}$.

The germination time had a significant effect $(P<0.05)$ on the preference of RKSBM viscosity (Figure 1). The highest viscosity preference level (3.59) was found in RKBSM with a $30 \mathrm{~h}$ germination time. If compared to the RKBSM made without going through germination, the preference level was very different $(P<0.05)$. It was likely related to the panelists' preference for non-thick (thin) drinks. This finding supports the opinion of Yogesh and Ali (2014) that the 
milk made from germinated mung beans was preferred by panelists than the one made from the un-germinated mung beans. The milk made from the germinated mung beans had a lower viscosity than the one made from the un-germinated mung beans. Therefore, the longer the germination time, the thinner the RKBSM viscosity and the more favored by the panelists.

The germination time had a significant effect $(P<0.05)$ on the preference level of RKBSM color (Figure 1). The highest color preference level (3.63) was found in the RKBSM with a $30 \mathrm{hr}$ germination time. It might be related to the decreasing viscosity of the product with the longer germination time; thereby, the milk color became clearer. This result was in line with the opinion of Pertiwi et al. (2013) who stated that the germination time affected the color preference of black soybean sprout milk. The longer the germination time, the brighter the color of the RKBSM. Conversely, the shorter the germination time, the darker the color. This condition occurred because all pigments (one of them was anthocyanin) in the husk of black soybean sprouts dissolved when extracted at the beginning of germination. The darkness of the color faded with longer germination time. This finding was contrary to the opinion of Ojha et al. (2014) who stated that the germination time did not affect the color of the tofu made from germinated-soybean milk and the one made from un-germinated-soybean milk because both of them had very similar base colors (i.e. white). This opinion was similar to Murugkar (2014) who asserted that the germination did not affect the color preference of soybean sprout milk because the milk made from germinated soybeans and the one made from ungerminated soybeans had similar colors.

The results showed that the germination time had a significant effect $(P<0.05)$ on the preference of RKBSM flavor (Figure 1). The product with $20 \mathrm{hrs}$ germination time had the most preferred flavor (with a score of 3.16), but this result was not different from the one with $30 \mathrm{hrs}$ germination time $(P>0.05)$. The flavor was related to the beany flavor or the unpleasant odor of the beans. The unpleasant flavor of the red kidney beans might decrease significantly after $20 \mathrm{hrs}$ of germination. The loss of the unpleasant flavor made consumers could consume RKBSM with a pleasant flavor. This finding was in line with the opinion of Pertiwi et al. (2013) who stated that the germination time affected the preference of the flavor of black soybean sprout milk, which was related to the decrease in the unpleasant flavor. If compared to the ungerminated RKBSM, the panelists tended to prefer the flavor of the milk made from germinated beans. Ojha et al. (2014) asserted that the tofu made from soy milk that had been germinated for $12 \mathrm{hrs}$ was preferred to the tofu made from the un-germinated-soybean milk due to the stronger unpleasant flavor.

\subsection{Total phenolic content of RKBSM}

The germination time affected the total phenolic content of RKBSM $(P<0.05)$. The longer the germination time, the higher the total phenolic content. The highest total phenolic content $(583.85 \mathrm{mg} / \mathrm{L})$ was found in the RKBSM with a $30 \mathrm{hrs}$ germination time (Figure 2). This finding was in line with the opinions of López-Amorós et al. (2006) who stated that the germination improved the quality of legumes. The germination not only decreased the anti-nutrients but also increased the amino acids, carbohydrates, dietary fiber, and bioactive compounds (including the phenolic compounds) contents.

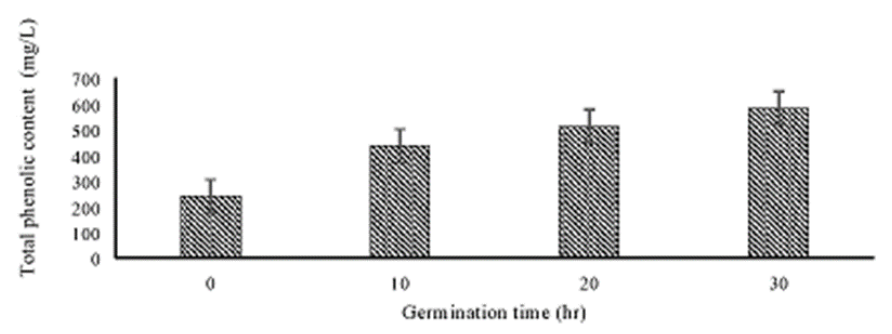

Figure 2. Effect of germination times on total phenolic content of red kidney bean sprouts milk. $0 \mathrm{hr}$, Ungerminated red kidney beans; $10 \mathrm{hrs}$, Red kidney beans germinated for $10 \mathrm{hrs;}$ $20 \mathrm{hrs}$, Red kidney beans germinated for $20 \mathrm{hrs;} 30 \mathrm{hrs}$, Red kidney beans germinated for $30 \mathrm{hrs}$.

An increase in phenolic content after $30 \mathrm{hrs}$ germination may be due to the association between enzyme activity and water availability. The water absorption activates the stored enzymes and then stimulates growth. The enzymes hydrolyze some of the reserve substances into energy and reduce the weight of molecules and soluble compounds used to produce tissue cells. The enzyme hydrolysis is also the impact of adding more water, which strengthens the enzyme-substrate interaction to produce more new products (phenolic). Phenolic compounds are reported to be very suitable for protecting cell membranes against damage caused by reactive free radicals. These compounds can also reduce LDL aggregation (Fernandez-Orozco et al., 2006) which is the cause of cardiovascular heart disease (CHD). The phenolic compounds are not only effective in preventing oxidation in food, but they also act as a protective factor against oxidative damage in the human body. Epidemiological studies showed that consumption of phenolic-rich foods correlated with a decrease in the incidence of CHD, inflammation, and cancer (Ardekani et al., 2011) which were associated with the development of MetS. Fernandez-Orozco et al. (2006) also reported that the germination increased the total phenolic content, 
total peroxyl radical-trapping capacity (16-55\%), and Trolox equivalent antioxidant capacity (12-23\%). The germination also inhibited the lipid peroxidation. Thus, the total phenolic content contributes to total antioxidant capacity. Besides bioactive phenolic compounds, legumes also contain vitamins and carotenoids which have antioxidant properties. The activity of these compounds synergizes with the phenolic compounds to enhance their antioxidant activities.

\subsection{Soluble protein content of RKBSM}

The germination time affected the soluble protein content of RKBSM $(P<0.05)$. The highest protein content $(33.65 \%)$ was found in RKBSM with a $30 \mathrm{hr}$ germination time, but the protein content was not different from the RKBSM with a $20 \mathrm{hr}$ germination time $(P>0.05)$. This finding supported the study by Afify et al. (2012) who stated that the soluble protein content increased significantly during germination. The increased protein content occurred because the germination increased the activity of intrinsic enzymes (e.g., amylase, protease, phytase, and fiber-breaking enzymes) which eventually improved nutrient digestibility. Besides increasing protein digestibility, the germination also improves the sensory properties of the product. Water-soluble proteins are generally in the form of oligopeptides that have less than ten amino acid chains, and they are easily absorbed by the digestive system. The increase in soluble protein content occurs because the germination activates the protease. The protein is degraded by protease into soluble amino acids with a smaller molecular weight; thereby increasing the protein digestibility value (Ojha et al., 2014). The strong bonds between the constituent components of the protein are detached which allows the protein content and digestibility to increase. Protein digestibility is a determinant of protein quality in foodstuffs. The greater the number of amino acids released by the digestion system within a certain limit, the higher the protein digestibility. Winarsi et al. (2016) added that the germination time affected the protein content of soybeans. The protein content in the flour of soybeansprout protein isolate was $42 \%$, greater than its content in soy protein isolate flour $(36.5 \%)$. Ojha et al. (2014) showed that the tofu made from soybean sprout milk had a higher soluble protein content than the one made from the un-germinated-soybean milk. It was similar to the statement of Luo and Xie (2014) that the soluble protein content in green and white fava beans germinated for 72 $\mathrm{h}$ also increased. Based on these opinions, there is a possibility that the protein content of RKBSM can increase even more if the germination time is lengthened.

\subsection{The selected RKBSM formula}

The effectiveness index testing was conducted to determine the best formula (DeGarmo et al., 1984). The highest effectiveness value (0.94) was obtained from the RKBSM with a $30 \mathrm{hrs}$ germination time based on the effectiveness index test with weight parameters as follows: 1 for total phenolic, 0.9 for soluble protein, 0.8 for flavor, 0.7 for taste, 0.6 for color, and 0.5 for viscosity. The moisture, ash, and fat contents of the selected RKBSM formula were $88.4 \%, 0.04 \%$, and $0.1 \%$, respectively. The selected RKBSM had high protein content $(6.54 \%)$ and low carbohydrate content $(4.48 \%)$.

The protein of the selected RKBSM is three times higher than the minimum limit of soy milk protein $(2 \%)$ in the SNI (1992). Protein had a greater thermogenic and satiety effect than carbohydrates. The protein of RKBSM formed a greater calorie expenditure than carbohydrates. Therefore, the protein could suppress hunger and appetite which eventually decreased the body weight. Winarsi et al. (2019) reported that a high-protein diet produced a longer feeling of fullness than a low-protein diet; thereby suppressing the next energy intake. This condition occurred because the body did not have protein storage. Thus, the protein was immediately metabolized into energy. Therefore, it was important to do the germination before the RKBSM was made. Fidelis et al. (2014) added that the red kidney beans which were processed into dairy products had a better taste than the milk made from soybeans, peanuts, mung beans, or cowpea. The fat content of selected RKBSM was low; i.e., one-tenth of the minimum limit of the soy milk fat content (1\%) determined by SNI (1995). The low-fat content in selected RKBSM could limit the energy intake. The fat deposits of the RKBSM were also low. The RKBSM also has another advantage. It can be a substitute for cow milk for people who have lactose intolerance. These advantages make the RKBSM has the potential as a functional drink for people with MetS.

\subsection{The anti-inflammatory activity of RKBSM}

The percentage increase in the volume of edema for various time observations is shown in Figure 3. In the negative control group, the volume of edema increased up to $240 \mathrm{~min}$. This proves that carrageenan is capable of being an inflammatory inducer. Amdekar et al. (2011) confirm that carrageenan as an inflammatory inducer reaches its peak at the $4^{\text {th }}$ hour so that the feet of rats experience a maximum increase in volume. The increase is related to the release of histamine, serotonin, and bradykinin after carrageenan induction. While in the positive control group the maximum increase in edema volume occurred in the $60^{\text {th }} \mathrm{min}$, then decreased to $240^{\text {th }}$ 
min. Oral diclofenac can provide an anti-inflammatory effect after $1 \mathrm{hr}$ which inhibits the formation of inflammatory mediators such as prostaglandins and leukotrienes.

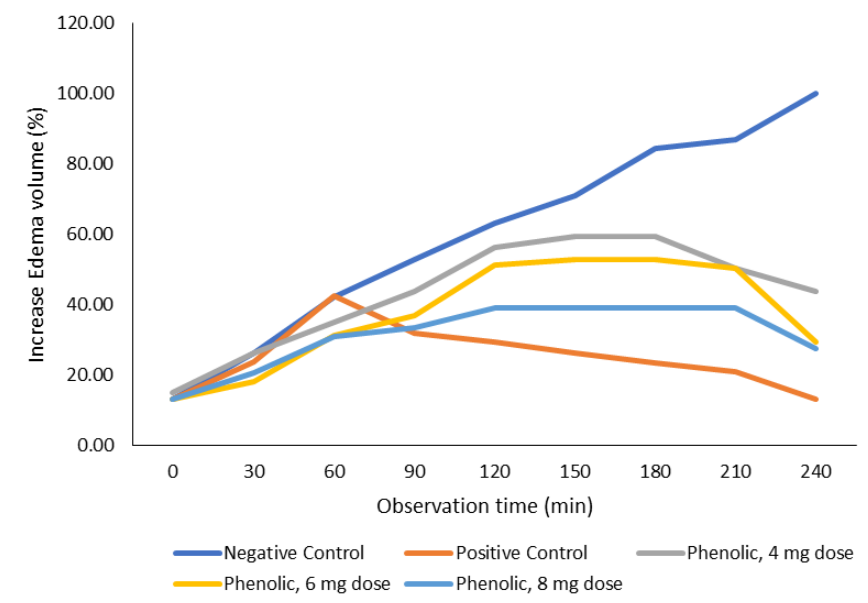

Figure 3. The effect of phenolic of red kidney bean sprout milk on edema volume of carrageenan-induced rats.

In the group that was intervened with RKBSM with phenolic levels of 4 and $6 \mathrm{mg} / \mathrm{Kg} \mathrm{BW}$, the volume of edema decreased after $180 \mathrm{mins}$, while the dose of $8 \mathrm{mg} /$ $\mathrm{Kg}$ BW decreased after 210 mins. The results of this study are following the findings of Anilkumar et al. (2017) who stated that administration of total phenolic at a dose of $4.1 \mathrm{mg} / \mathrm{Kg} \mathrm{BW}$ reduced the volume of edema at the $3^{\text {rd }}$ hour. Data on the increasing volume of edema can be used to calculate the Area Under Curve (AUC) of each group, then to determine the percentage of antiinflammatory potency (Table 1).

The AUC value describes a decrease in the volume of edema in the rat feet. Therefore, the smaller the AUC value, the smaller the increase in the volume of rat feet edema, the greater the ability to reduce the volume of the edema. The AUC value in the negative control is the highest, while the lowest positive control. It because given in the negative control group only distilled water, did not have an anti-inflammatory effect. The negative AUC control values differed significantly from the positive control group, as well as the RKBSM treatment group with a total phenolic $8 \mathrm{mg}(P<0.05)$. But the AUC positive control did not differ from the group dose $8 \mathrm{mg} /$ $\mathrm{Kg}$ BW $(P>0.05)$, meaning that RKBSM with a total phenolic dose of $8 \mathrm{mg} / \mathrm{Kg} \mathrm{BW}$ has the potential for antiinflammatory (lowering the volume of carrageenaninduced foot edema) which is the same as diclofenac sodium.

Table 1 also presents the percentage of the antiinflammatory power of RKBSM. The highest percentage of anti-inflammatory potency ( $\%$ AIP) in the positive control group was $55.73 \pm 2.6 \%$, compared to giving RKBSM. The largest percentage of AIP was found in RKBSM with a phenolic dose of $8 \mathrm{mg} / \mathrm{Kg}$ BW was $44.74 \%$, while the smallest was found in a dose of $4 \mathrm{mg} /$ $\mathrm{Kg} \mathrm{BW}$ was $23.03 \%$. The greater the dose of phenolic given, the greater the $\%$ AIP produced. Thus the antiinflammatory effect of RKBSM depends on the amount of the phenolic dose given. The anti-inflammatory potential of RKBSM was faster (4 hrs) than Reverri et al. (2015) reported that in black bean the potential was seen in the range of 36-48 hrs.

Anti-inflammatory activity was also observed based on the motility score of experimental animals during inflammation (Amdekar et al., 2011). The greater the motility score, the better the rat runs (without teetering), the greater the anti-inflammatory effect. The highest motility score is in the positive control group $(1.73 \pm 0.44)$, while the lowest is the negative control group which was $1.00 \pm 0.59$ (not significantly different from the $4 \mathrm{mg} / \mathrm{Kg} \mathrm{BW}$ group) $(P>0.05)$. There was a significant difference between positive controls group and all treatments of milk red bean sprouts $(P<0.05)$ in improving the rat behavior. The highest motility score was found in the treatment of RKBSM dose of $8 \mathrm{mg} / \mathrm{Kg}$ BW which was equal to 1.42 . Thus, the greater the phenolic dose is given, the greater the motility score obtained, the better the rat runs (without teetering), so the anti-inflammatory potential was higher. Red kidney bean sprout milk has anti-inflammatory activity associated with the presence of total phenolic content in it. Therefore, RKBSM is very potential to be developed as a health drink rich in antioxidants that have the potential to be anti-inflammatory.

The selected RKBSM formula with a $30 \mathrm{hrs}$ germination time had color, taste, flavor, and viscosity scores of 3.6, 3.21, 3.16, and 3.59 (between neutral and

Table 1. Area under curve and motility score of inflammatory carrageenan-induced rats

\begin{tabular}{lccc}
\hline \multicolumn{1}{c}{ Treatment group } & AUC \pm SD & AIP $(\%)$ & Motility Score \pm SD \\
\hline Negative control & $1773.84 \pm 746.38^{\mathrm{b}}$ & - & $1.00 \pm 0.59^{\mathrm{a}}$ \\
Positive control & $784.45 \pm 254.74^{\mathrm{a}}$ & $55.73^{\mathrm{a}}$ & $1.73 \pm 0.44^{\mathrm{b}}$ \\
RKBSM with 4 mg total phenolic & $1362.2 \pm 411.821^{\mathrm{ab}}$ & $23.03^{\mathrm{b}}$ & $1.06 \pm 0.62^{\mathrm{ac}}$ \\
RKBSM with 6 mg total phenolic & $1181.24 \pm 408.94^{\mathrm{ab}}$ & $33.38^{\mathrm{c}}$ & $1.24 \pm 0.43^{\mathrm{d}}$ \\
RKBSM with 8 mg total phenolic & $983.33 \pm 279.58^{\mathrm{a}}$ & $44.74^{\mathrm{d}}$ & $1.42 \pm 0.49^{\mathrm{e}}$ \\
\hline
\end{tabular}

RKBSM, red kidney bean sprout milk; AUC, Area under Curve; AIP, anti-inflammatory potency. Different superscript letters indicate a significant difference in a column. 
moderately like) respectively, and rich in phenolic antioxidants $(583.85 \mathrm{mg} / \mathrm{L})$, protein $(6.54 \%)$, and soluble protein $(33.65 \%)$, but low in fat $(0.1 \%)$ and carbohydrates $(4.48 \%)$. This RKBSM rich in phenolic antioxidants also has anti-inflammatory effects. The higher the phenolic dose in the RKBSM ( $8 \mathrm{mg} / \mathrm{Kg} \mathrm{BW}$ ), the higher the anti-inflammatory potency $(44.74 \%)$ and the motility score (1.42). High levels of RKBSM protein, allowing antioxidant-rich products to have a positive impact on lipid profiles and making it suitable for patients with inflammatory symptoms such as those with MetS.

\section{Conflict of Interest}

The authors declare no conflict of interest.

\section{Acknowledgments}

The authors would like to express their gratitude to the Directorate General of Development and Research Enhancement of the Ministry of Research, Technology and Higher Education of Indonesia, who has funded this study through the Competency-Based Research scheme with contract number 1637/UN23.14/PN.01.00/2018, in the year 2018 .

\section{References}

Afify, A.E.M.M.R., El-Beltagi, H.S., El Salam, S.M.A. and Omran, A.A. (2012). Protein solubility, digestibility, and fractionation after germination of sorghum varieties. PLoS One, 7, e31154. https:// doi.org/10.1371/journal.pone.0031154

Amdekar, S., Roy, P., Singh, V., Kumar, A., Singh, R. and Sharma, P. (2012). Anti-inflammatory activity of Lactobacillus on carrageenan-induced paw edema in male Wistar Rats. International Journal of Inflammation, 2012, $752015 . \quad \mathrm{https} / / /$ doi.org/10.1155/2012/752015

Amirdivani, S. and Baba, A.S. (2015). Green tea yogurt: major phenolic compounds and microbial growth. Journal of Food Science and Technology, 52, 46524660. https://doi.org/10.1007/s13197-014-1670-6

Anilkumar, K., Reddy, G.V., Azad, R., Yarla, N.S., Dharmapuri, G., Srivastava, A., Kamal, M.A. and Pallu, R. (2017). Evaluation of Anti-Inflammatory Properties of Isoorientin Isolated from Tubers of Pueraria tuberosa. Oxidative Medicine and Cellular Longevity, 2017, 5498054. https:// doi.org/10.1155/2017/5498054

Ardekani, M.R.S., Hajimahmoodi, M., Oveisi, M.R. and Moridi, T. (2011). Comparative antioxidant activity and total flavonoid content of Persian pomegranate (Punica granatum L.) cultivars. Iranian Journal of
Pharmaceutical Research, 10(3), 519-524.

Chaudhary, N., Vyas, S. and Joshi, I. (2013). Biochemical and enzymatic changes associated with duration of germination of wheat moth based food mixes. International Journal of Science and Research, 4(2), 2267-2271.

DeGarmo, E.P., Sullivan, W.G. and Canada, J.R. (1984). Engineering Economy. $7^{\text {th }}$ ed., p. 79-96. New York, USA: Macmillan Pub. Co,

Fernandez-Orozco, R., Piskula, M.K., Zielinski, H., Kozlowska, H., Frias, J. and Vidal-Valverde, C. (2006). Germination as a process to improve the antioxidant capacity of Lupinus angustifolius L. var. Zapaton. European Food Research and Technology, 223, 495. https://doi.org/10.1007/ s00217-005-0229-1

Fidelis, K.M.K., Emmanuel, A.O., Betty, A.B. and Firibu, S.K. (2014). Nutritional and sensory characterization of full fat and partially defatted peanut soy milk yoghurt. International Journal of Nutrition and Food Sciences, 3(3), 187-193. https:// doi.org/10.11648/j.ijnfs.20140303.19

Hayat, I., Ahmad, A., Masud, T., Ahmed, A. and Bashir, S. (2013). Nutritional and Health Perspectives of Beans (Phaseolus vulgaris L.). An Overview. Critical Reviews in Food Science and Nutrition, 54 (5), 580-592. https:// doi.org/10.1080/10408398.2011.596639

Kiyani-Sam, M., Amjad, L. and Ranjbar, M. (2015). Comparative study of antioxidant activity, phenol and flavonoid content in Phaseolus vulgaris and Vigna sinensis in different stages of seed germination. International Journal of Biosciences, 6, 292-297. https://doi.org/10.12692/ijb/6.5.292-297

López-Amorós, M. L., Hernández, T. and Estrella, I. (2006). Effect of germination on legume phenolic compounds and their antioxidant activity. Journal of Food Composition and Analysis, 19(4), 277283. https://doi.org/10.1016/j.jfca.2004.06.012

Luo, J., Cai, W., Wu, T. and $\mathrm{Xu}, \mathrm{B}$. (2016). Phytochemical distribution in hull and cotyledon of adzuki bean (Vigna angularis L.) and mung bean (Vigna radiate L.), and their contribution to antioxidant, anti-inflammatory and anti-diabetic activities. Food Chemistry, 201, 350-360. https:// doi.org/10.1016/j.foodchem.2016.01.101

Luo, Y. and Xie, W. (2014). Effect of soaking and sprouting on iron and zinc availability in green and white faba bean (Vicia faba L.). Journal of Food Science and Technology, 51, 3970-3976. https:// doi.org/10.1007/s13197-012-0921-7

Moskowitz, H.R., Beckley, J.H. and Resurreccion, 
A.V.A. (2012). Sensory and Consumer Research in Food Product Design and Development, p. $283-$ 319. San Franciso, USA: Wiley-Blackwell. https:// doi.org/10.1002/9781119945970

Murugkar, D.A. (2014). Effect of sprouting of soybean on the chemical composition and quality of soymilk and tofu. Journal of Food Science and Technology, 51(5), 915-921. https://doi.org/10.1007/s13197-0110576-9

Nguyen, T.Y., To, D.C., Tran, M.H., Lee, J.S., Lee, J.H., Kim, J.A., Wooa, M.H. and Min, B.S. (2015). Antiinflammatory Flavonoids Isolated from Passiflora foetida. Natural Product Communications, 10(6), 929-931.

doi.org/10.1177/1934578X1501000634

Ojha, P., Karki, T.B. and Maharjan, S. (2014). Effect of sprouting in physicochemical properties of tofu. Journal of Nutritional Health and Food Engineering, 1(2), $\quad$ 65-72. jnhfe.2014.01.00011

Okereke, A. (2008). Functional properties of processed pigeon pea (Cajanus cajan) flour. International Journal of Tropical Agriculture and Food Systems, 2, 3-4. https://doi.org/10.4314/ijotafs.v2i3-4.50005

Oomah, B.D., Corbé, A. and Balasubramanian, P. (2010). Antioxidant and anti-inflammatory activities of bean (Phaseolus vulgaris L.) hulls. Journal of Agricultural and Food Chemistry, 58, 8225-8230. https://doi.org/10.1021/jf1011193

Pertiwi, S.F., Aminah, S. and Nurhidayah. (2013). Antioxidant activity, chemical characteristics, and organoleptic properties of black soybean sprouts (Glycine soja) based on germination time variations. Jurnal Pangan dan Gizi, 4, 10-21.

Pomory, C.M. (2008). Color development time of the Lowry protein assay. Analytical Biochemistry, 378 (2), 216-217. https://doi.org/10.1016/ j.ab.2008.04.015

Pradeepkumar, M.R., Joshi, S.D., Kulkarni, V.H. and Savant, C. (2015). Phytochemical screening and evaluation of analgesic and anti-inflammatory activities of Phaseolus vulgaris linn., seeds in rodents. Journal of Applied Pharmaceutical Science, 5(6), $\quad$ 066-069. https://doi.org/10.7324/ JAPS.2015.50610

Reverri, E.J., Randolph, J.M., Steinberg, F.M., Kappagoda, C.T., Edirisinghe, I. and BurtonFreeman, B.M. (2015). Black beans, fiber, and antioxidant capacity pilot study: Examination of whole foods vs. functional components on postprandial metabolic, oxidative stress, and inflammation in adults with metabolic syndrome. Nutrients, 7(8), 6139-6154. https:// doi.org/10.3390/nu7085273

Singh, A., Malhotra, S. and Subban, R. (2008). Antiinflammatory and analgesic agents form Indian medicinal plants. International Journal of Integrative Biology, 3(1), 57-72.

Vazirian, M., Dianat, S., Manayi, A., Ziari, R., Mousazadeh, A., Habibi, E., Saeidnia, S. and Amanzadeh, Y. (2014). Anti-inflammatory effect, total polysaccharide, total phenolic content and antioxidant of the aqueous extract of three Basidiomycetes. Research Journal of Pharmacognosy, 1(1), 15-21.

Winarsi, H., Sasongko, N.D. and Purwanto, A. (2016). Germinated-soy milk in suppressing inflammation and oxidative stress in blood plasma and breast milk of lactating mothers. International Food Research Journal, 23(2), 646-652.

Winarsi, H., Sasongko, N.D. and Purwanto, A. (2019). Germinated-soy milk as a healthy diet to induce high antioxidant enzymes in breast milk. IOP Conference Series: Earth and Environmental Science, 255, 012034. https://doi.org/10.1088/1755$1315 / 255 / 1 / 012034$

Winarsi, H., Wijayanti, S.P.M. and Purwanto, A. (2012). Soy germ protein with or without-Zn improves plasma lipid profile in metabolic syndrome women. HAYATI Journal of Biosciences, 19(1), 25-30. https://doi.org/10.4308/hjb.19.1.25

Yogesh, K. and Ali, J. (2014). Effect of mung bean and sprouted mung bean (Vigna radiata) powder on chicken breast meat tenderness, microbial and sensory characteristics. Journal of Food Science and Technology, 51, 1411-1415. https://doi.org/10.1007/ s13197-012-0650-y 